DOI: https://doi.org/10.3126/njdrs.v17i0.34950

\title{
Governance for Sustainability of Rural Water Supply and Sanitation Schemes (RWSS): The Case from NAPA ${ }^{1}$-WASH
}

\author{
Keshab Prasad Adhikari, PhD \\ Associate Professor of Population Studies and Coordinator of Labour Studies Programme, \\ Tribhuvan University, Kirtipur, Kathmandu \\ E-mail for correspondence: adhikarikpa@gmail.com
}

\begin{abstract}
Water and sanitation are taken at the heart of achieving a number of goals and critical targets of sustainable development goals. But achieving sustained water and sanitation service in a rural context is problematic from the viewpoint of technical, financial, environmental, and social, and governance aspects of functionality. Therefore, good governance in the operation and management of rural water and sanitation schemes are a key component to determine the other aspects of functioning and longerterm sustainability. The study sees the working of five indicators of functionality, five layers of priority ranking indicators, four service indicators of quantity, accessibility, reliability, and quality (QARQ), and ten indicators of assessing governance level sustainability. In all aspects of assessment, most RWSS found to stand at the level of partial sustainability. This urged for giving higher priority to upgrading such schemes in the status of full sustainability.
\end{abstract}

Key words: Households, governance, rural, sanitation, sustainability, water

\section{The Context}

Water is the most essential natural gift and owes immense importance to the health, sanitation, and social and economic wellbeing of the populations worldwide. Though, it is a common natural commodity, has private importance among individuals. Reliable access to enough of the commodity meeting the quality standard (safe and secure) has multilevel social and economic implications. Long-term sustainability is a concept that has gained considerable attention in declining natural resources. At the basic level, its concern is to improve the survival of the dwindling natural resources in the future - ensuring resources used are responsibly managed and maintained. It is believed that the long-term sustainability is a major factor in the long-term success in natural resource management. Social and governance aspects are crucial inputs in long term sustainability of water resource management of the rural water supply, and sanitation schemes (RWSS) in Nepal.

The term long-term sustainability is defined as the "management and conservation of the natural resource base, and the orientation of technological and institutional change in such a manner to ensure the attainment and continued satisfaction of human needs for present and future generations. Such sustainability includes conservation of land, water, plant and animal genetic resources, environmentally non-degrading, technologically appropriate, economically viable and socially acceptable". The United

1 Nawalparasi and Palpa

Nepalese Journal of Development and Rural Studies, Volume 17 
Nations Environment Programme(UNEP) defines sustainable development as 'development that ensures that the use of resources and the environment today does not compromise their use in the future'. Worthwhile to note here the innovative elements for the longer-term sustainable water policy of the European Water Framework Directive (WFD, 2000) as a) integrated approach expanding the scope of water protection to all waters, surface waters, and groundwater, b) the hydrological principle where water management is based on river basins, c) the obligation to achieve a "good status", d) a "combined approach" of emission limit values and quality standards, e) getting the prices right by introducing the principle of cost recovery, and f) getting citizens involved more closely by prescribing public participation in the development and implementation of water resource management (PahlWostl, Mostert, \& Tabara, 2008). These points out that wider community participation and ownership and governance aspects of the schemes account more in the achievement of the long-term sustainability of the commodity.

Though the coverage of the water and sanitation schemes in rural areas of Nepal accorded to increase substantially, pertinent problems the sector is suffering with as accounted by the Ministry of Urban Development (20014) are:

- The poor functionality of completed scheme. About half of the schemes are non-functioning and are in urgent needs of massive maintenance

- The growth of the previously rural settlements as urban centres after the development of water and sanitation schemes and being the system grossly inadequate in many of the rural communities due to increased population and improved living standards of the people

- Most of the rural water supplies in hilly areas are designed and operated based on small surface and sub-surface sources with very marginal dry weather discharges. Such small sources are prone to dry out for the slightest change in climatic, geotechnical, and vegetation of their catchment due to natural or human causes, and

- A dispute among the competing user community in the scarce source because of the absence of a scientific and comprehensive water resource planning at local levels.

- Ownership for planning, implementation, management, and maintenance if given to the local users' communities, then believed to enhance wider community participation, enhance practices of good governance and scaleup scheme's functioning towards long-term sustainability.

\section{Components of Sustainability of RWSS}

The central to the concept of sustainability of any development schemes are meeting both present and future needs through a balance of three components: maintenance of a healthy and equitable society, protection of the environment, and ongoing prosperity of the local economy. In the context of the implementation strategy of RWSS in Nepal, taking reference to NAPA-WASH, it seems to have well addressed the three interdependent and mutually reinforcing pillars i.e. economic development, social harmony, and environmental protection (Figure 1). These components are interrelated and equally important in achieving a suntanned community-managed RWSS. Ultimately, one component should not succeed at the expense of another, so a key issue is how to balance these components over the life of a development plan. 


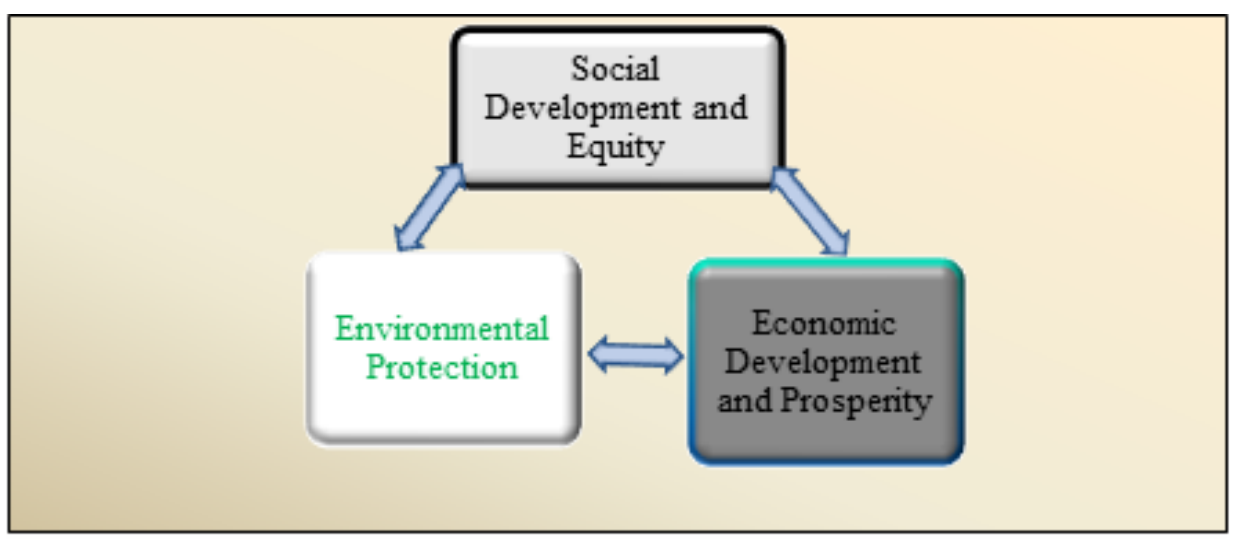

\section{Figure 1. Interdependence among Three Pillars of Sustainability}

The longer-term sustainability approaches adopted in the RWSS schemes include technical and functionality at the community level; social institutions for the management; financial capacity and willingness to pay; managerial capacity of the schemes; linkages of the schemes with local to central government network and external support agencies and the external shocks of environmental catastrophes and the like (Table 1). The components of the RWSS that look at the social and governance level of sustainability include, institutional capacity, information dissemination schemes, linkages with other relevant associations, timeliness in annual general meeting and participatory approach of discussion in agenda, modes of committee formation and inclusiveness, and the like. WASH sector sustainability is suggested to review based on indicators (Table 1).

Table 1. Components of WASH Sector Sustainability and Indicators of Measure

\begin{tabular}{|c|c|}
\hline Components of Sustainability & Indicators to Measure \\
\hline Technical sustainability & $\begin{array}{l}\text { Technical soundness, appropriate solutions, technical training for } \\
\text { operations and maintenance, access to and cost of spare parts and } \\
\text { repairs }\end{array}$ \\
\hline $\begin{array}{l}\text { Economic/financial } \\
\text { sustainability }\end{array}$ & $\begin{array}{l}\text { Resilience to economic shocks; financial viability, reduced } \\
\text { household vulnerability, and increased capacity to cope with risk/ } \\
\text { shocks }\end{array}$ \\
\hline Institutional sustainability & $\begin{array}{l}\text { Institutional support; policy implementation; staffing and recurrent } \\
\text { budgets }\end{array}$ \\
\hline Social sustainability & $\begin{array}{l}\text { Social support and acceptability, community commitment, social } \\
\text { cohesion }\end{array}$ \\
\hline Political sustainability & $\begin{array}{l}\text { Government commitment; enabling policy environment; stakeholder } \\
\text { interests; strong lobby groups and political influence/pressure }\end{array}$ \\
\hline Ownership & $\begin{array}{l}\text { Level of acceptance of user communities, local government, and } \\
\text { households and own the outcomes of the project in sustainable ways }\end{array}$ \\
\hline Environmental sustainability & $\begin{array}{l}\text { Projects'positive/negative contributions to soil and waterpreservation } \\
\text { and management and resilience to external environmental shocks }\end{array}$ \\
\hline
\end{tabular}




\section{WASH at the Heart of MDGs and SDGs}

The Millennium Development Goals (MDGs) accorded the increasing access to domestic water supply and sanitation services as catalytic elements to fight poverty and hunger, safeguard human health, reduce child mortality, promote gender equality, and manage and protect natural resources. They, therefore, were taken as the critical component to achieving the integrated set of eight goals and eighteen goals specific, time-bound targets (Lenton, Lewis and Wright, 2008). The seventh Millennium Development Goal focussed on environmental sustainability, and Target-10 was one of the three specific targets, that called by 2015 , a reduction in the proportion of people without sustainable access to safe drinking water and basic sanitation by half.

Following the same principles of MDG, goal six "Ensure Availability and Sustainable Management of Water and Sanitation for All" of the Sustainable Development Goals (SDGs) is devoted to the sustainable management of water and sanitation for all. The goal is based on extensive linking of water supply and sanitation management to improved health, family wellbeing, gender equality, child survival, and economic productivity. Achievement of this goal is based on major changes in existing water management - to harmonise governance, data collection and sharing policies, and the use of models and tools for long-term sustainability. This requires a full commitment from every nation, state, and community and all the stakeholders within them, as well as changes in infrastructure and policies that would have large financial and political costs.

Concerning the implementation of the water and sanitation goals and targets, the SDG Conference identified four main challenges related to the sustainability of the theme as 1) management of water sanitation and hygiene, 2) management of water resources, 3) management of water quality, and 4) risks management.Specific targets of SDG Goal-6 and their instrumental interlinkages in meeting other goals are schematically presented below (Box 1 \&Table 2):

Box 1. The Six Specific Targets and Two Technical Cooperation and Capacity-Building Related Targets of SDG Six on Water and Sanitation

6.1: Achieve universal and equitable access to safe and affordable drinking water for all.

6.2: Achieve access to adequate and equitable sanitation and hygiene for all, and end open defecation, paying special attention to the needs of women and girls and those in vulnerable situations.

6.3: Improve water quality by reducing pollution, eliminating dumping and minimising release of hazardous chemicals and materials, halving the proportion of untreated wastewater, and increasing recycling and safe reuse by $\mathrm{x} \%$ globally.

6.4: Substantially increase water-use efficiency across all sectors and ensure sustainable withdrawals and supply of freshwater to address water scarcity, and substantially reduce the number of people suffering from water scarcity.

6.5: Implement integrated water resources management at all levels, including through transboundary cooperation as appropriate.

6.6: Protect and restore water-related ecosystems, including mountains, forests, wetlands, rivers, aquifers, and lakes.

Technical Cooperation and Capacity-Building

6. A: Expand international cooperation and capacity-building support to developing countries in water and sanitation-related activities and programmes, including water harvesting, desalination, water efficiency, wastewater treatment, recycling, and reuse technologies. 
6. B: Support and strengthen the participation of local communities in improving water and sanitation management.

Other proposed goals also include different water and sanitation targets as following:

3.3: by 2030 end the epidemics of AIDS, tuberculosis, malaria, and neglected tropical diseases and combat hepatitis, water-borne diseases, and other communicable diseases.

3.9: by 2030 substantially reduce the number of deaths and illnesses from hazardous chemicals and air, water, and soil pollution and contamination.

11.5: by 2030 significantly reduce the number of deaths and the number of affected people and decrease by $\mathrm{y} \%$ the economic losses relative to GDP caused by disasters, including waterrelated disasters, with the focus on protecting the poor and people in vulnerable situations;

12.4: by 2020 achieve environmentally sound management of chemicals and all wastes throughout their life cycle following agreed international frameworks and significantly reduce their release to air, water and soil to minimize their adverse impacts on human health and the environment.

15.1: by 2020 ensure the conservation, restoration, and sustainable use of terrestrial and inland freshwater ecosystems and their services, in particular forests, wetlands, mountains, and dry lands, in line with obligations under international agreements.

15.8: by 2020 introduce measures to prevent the introduction and significantly reduce the impact of invasive alien species on land and water ecosystems, and control or eradicate the priority species.

Table 2. Directly and Indirectly Contributory Water and Sanitation Related Goal of SDGs for the Achievement of Other SDGs

\begin{tabular}{|c|c|c|c|}
\hline \multirow[t]{3}{*}{ SDG } & Directly WASH Linked SDGs & SDG & Indirectly WASH Linked SDGs \\
\hline & $\begin{array}{l}\text { End hunger, achieve food security and } \\
\text { improved nutrition, and promote sustainable } \\
\text { agriculture: } \\
\text { - Water is essential to increase agricultural } \\
\text { productivity and industrial food processing }\end{array}$ & 1. & $\begin{array}{l}\text { End poverty in all its forms everywhere: } \\
\text { - Water is a factor for economic development } \\
\text { at all levels and for all users }\end{array}$ \\
\hline & $\begin{array}{l}\text { Ensure healthy lives and promote well-being } \\
\text { for all at all ages: } \\
\text { - Clean water is essential for human health }\end{array}$ & 4. & $\begin{array}{l}\text { Ensure inclusive and equitable quality } \\
\text { education and promote lifelong learning } \\
\text { opportunity for all: } \\
\text { - Providing sanitation in schools is key to } \\
\quad \text { keeping girls in school }\end{array}$ \\
\hline 5. & $\begin{array}{l}\text { Achieve gender equality and empower all } \\
\text { women and girls: } \\
\text { - Relieving the burden of women - who } \\
\text { spend excessive time accessing safe water } \\
\text { for their families }\end{array}$ & 8. & $\begin{array}{l}\text { Promote sustained, inclusive, and sustainable } \\
\text { economic growth, full and productive } \\
\text { employment, and decent work for all } \\
\text { - Water facilitates all types of economic } \\
\text { activity - secure water of proper quality is } \\
\text { essential for the development }\end{array}$ \\
\hline 7. & $\begin{array}{l}\text { Ensure access to affordable, reliable, } \\
\text { sustainable, and modern energy for all } \\
\text { - Water is essential for most forms of energy } \\
\text { production }\end{array}$ & 9. & $\begin{array}{l}\text { Build resilient infrastructure, promote } \\
\text { inclusive and sustainable industrialisation, and } \\
\text { foster innovation } \\
\text { - Infrastructure is needed for flood and } \\
\text { drought protection and water management }\end{array}$ \\
\hline
\end{tabular}


10. Ensure sustainable consumption and production patterns

- Consumption drives the industrial water demand. Cleaner production practices reduce water use and pollution emissions

12. Take urgent action to combat climate change and its impact

- Climate change affects water availability and sustainable water and sanitation development. Efforts of the UNFCC should be supported

14. Conserve and sustainable use the oceans and marine resources for sustainable development

- Develop management strategies to reduce fluvial erosion and pollution. These strategies could include a program of water rights/permits for pollution discharge

16. Protect, restore, and promote sustainable use of terrestrial ecosystems, sustainably manage forests, combat desertification, and halt and reverse land degradation and halt biodiversity loss

- Water in proper quantity and quality is needed to maintain ecosystems and ecosystems services
11. Reduce inequality within and among countries

- Water stress and water disasters reduce development opportunities. Basic human water rights must be assured by water transport

13. Make cities and human settlements inclusive, safe, resilient, and sustainable

- Water services (water supply and sanitation) must be a central part of urban planning and development

15. Promote peaceful and inclusive societies for sustainable development, provide access to justice for all, and build effective, accountable, and inclusive institutions at all levels

- International agreements and national strategies through programs such as water rights can promote the development of peaceful societies and institutions with meaningful roles

17. Strengthen the means of implementation and revitalize the global partnership for sustainable development

- Without the implementation of sustainable development for water, sustainable development in many other sectors would fail

(ICSU \& ISSC, 2015)

From the foregone discussion, it has been clear that the sustainable achievement of water and sanitation goals and targets (Goal 6 \& related targets) are viewed directly or indirectly to contribute to outcomes of all other goals and targets. Hence, it is imperative to see the sustainability of the Rural Water Supply and sanitation schemes in line with the sustainability components envisioned under different targets of goal six of the SDGs. It calls for sustainability on the ground of technical sustainability- safety, cleanliness, pollution-free; efficiency in water use; management sustainability, and financial management. The functional status of the completed RWSS then is indicative of the overall sustainability on the one hand and predictive outcome of the social and governance component of sustainability.

\section{Data and Methods}

Data for this analysis is used from the end line survey of the NAPA-WASH project, 20142017 conducted in December 2017. The survey covered 1,360 scheme's water user beneficiary households (680 from both districts), 80 water user and sanitation committees (40 each from both districts), interviews of 73 village maintenance workers, and 45 village development committees (22 of Nawalparasi \& 23 of Palpa). Indices of functional status and level of governance are computed creating 0,1 dichotomous binary variable. 


\section{Functional Status}

Functionality is the capacity of the water supply system to provide safe and sufficient drinking water to all users in the service area. Five indicators are developed to measure the functional status of the water supply system in terms of the number of taps functioning, a number of households served by a tap, the time required to collect water, and availability of water over the year, and perception of the users on the quality of the water supplied. The functionality of RWSS: Integrated training package for Post-Construction Support Service Team of SNV Nepal (2016), defines five indictors as following: Indicator 1: All the taps constructed at the start of the system should function. In case of some taps are not functioning, but users can collect water from other functioning taps, less than 20 percent tap not functioning is acceptable. Hence, if over 80 percent taps of the total established taps at the beginning of the scheme are found functioning at the time of the survey, the scheme is viewed as fully functional.

Indicator 2: Maximum households served from a tap were 10 at the time of construction of the scheme, which might have increased by 50 percent in some of the instances at the time of the survey. Hence, for a fully functional scheme, there should not be more than 15 households per functional taps sharing it.

Indicator 3: Tap flow should be sufficient to meet the peak demand of all sharing/using households of that tap. Design guideline requires a minimum flow of 0.1 litre per second (lps) in any case. This will require 65 seconds to fill up a 10-liter vessel. Desired tap flow for fully functioning is $0.15 \mathrm{lps}$ to maintain standard tap flow for 15 households, which requires $65 \mathrm{lps}$ for filling up a 10-liter vessel.

Indicator 4: Water should be available for all 365 days. Considering various risks, up to 30 total supplies breaking down days in a year for various reasons is acceptable for full functioning but breakdown should not occur for more than one day continuously, and not more than 20 percent of the taps should break down at the same time.

Indicator 5: Water quality in the functioning tap should be acceptable because of the user's perception all the time.

For a water supply system value for the indicators are calculated as the average of the whole system based on the past one-year scenario as reported by the users. The functional status of a system is labelled as fully functional with assigned score of 5, partially functional with an assigned score of 3 , and non-functional with an assigned score of 1 under each indicator. Any system meeting the functionality criteria on each indicator is ranked as fully functional. Similarly, a system meeting all criteria for partial functionality or anyone criterion for partial and other for partial or full functionality is ranked as partial functional; otherwise, it is ranked as non-functional. Criteria of labelling functionality status are determined below (Table 3). 
Table 3. Criteria of Levelling Scheme's Functionality by the Level of Indicators

\section{Functionality Status Indicator}

$\%$ Tap functioning

Average no. of working tap

Time to fill 10 litre water in the working tap

Water available months per year in the working tap

Perception on Quality of water in the working tap
Level of functionality

Fully functional (5) Partially functional Non-functional (1)

(3)

\begin{tabular}{|c|c|c|}
\hline$>80 \%$ & $21-80 \%$ & $\leq 20 \%$ \\
\hline$\leq 15 \mathrm{HH}$ & $16-24 \mathrm{HH}$ & $>24 \mathrm{HH}$ \\
\hline$\leq 65 \mathrm{sec}$ & $66-100 \mathrm{sec}$ & $>100 \mathrm{sec}$ \\
\hline$\geq 11$ months $*$ & $\geq 10$ months $* *$ & $<10$ months $* * *$ \\
\hline Always good & Mostly/Generally good & $\begin{array}{c}\text { Sometimes- good / } \\
\text { Never good }\end{array}$ \\
\hline
\end{tabular}

$\leq 20 \%$

$\leq 65 \mathrm{sec}$ per $\leq 15 \mathrm{HH}$

Use of functional indicators. WUSC always needs to strive for keeping the system fully
al by meeting all criteria. In case the status is not within the range of fully functional, they need functional by meeting all criteria. In case the status is not within the range of fully functional, they need to work out an improvement plan and implement it as early as possible. Improvement may refer to improving source capacity, repairs of pipes, repairs of tap stands, or addition of tap stands or improving operations. If design periods have surpassed rehab, reconstruction or extension of the system may be needed. The result was clear to see that nearly 69 percent of the schemes have 80 percent or more functional taps to the total taps constructed at the beginning of the scheme, indicating fully functional; nearly 23 percent of the schemes are having less than 20 percent functional taps and categorised as nonfunctional, and the rest nine percent of the schemes are in partially functional status. The proportion of fully functional taps is high in Palpa, the hill region, community resided by Brahman, Chhetri, and Thakuri, in small schemes. Fifty percent of the schemes in the Tarai region and 36 percent schemes of the Dalit communities are categorised as totally non-functional.

In nearly 87 percent of the schemes, a functional tap is shared by 15 or less number of households and labelled as fully functional. In another 11 percent of the schemes, a functional tap is shared by 16 to 24 households and categorised as partially functional, andsome two percent tap by 25 or more households. However, from the point of view of the time taken to fill up 10 litres of water, 49 percent of the taps were found discharging 10 litres of water or more in 65 seconds and labelled as fully functional and, 48 percent of them needed time between 66 and 100 seconds for the same and found as partially-functional. The rest, nearly two percent of the functional taps found yielding 10 litres of water in more than 100 seconds and categorised as non-functional.

Deducing all the water breakdown days round the year, functional taps of about 90 percent of the schemes reported to get water in tap for 11 and more months in a year and categorised as fully functional. Another six and four percent, respectively, as non-functional, and partially functional. The assumption is that user households should always rate the quality of water they getfrom the system as 'good'. If they view the quality of water in some period as 'poor', the water quality functionality is considered the poor period. Therefore, water quality during the wet or rainy season is taken as a predictor 
of it. From this point of view, in 63 percent cases, water quality is found partially functional (mostly/ generally of good quality), in 26 percent cases, it is of poor quality and labelled as non-functional and, the rest 10 and a half percent is taken as always of good quality, and functional.

\section{QAQR Service Level Sustainability}

The service level of the water supply system has been defined in terms of four indicators i.e. Quantity, Accessibility, Reliability, and Quality, denoted by QARQ (Table 4). Quantity is measured by the amount of water available to each person in a day. Accessibility is measured by the distance of a tap stand from the households and fetching time. Reliability is measured in terms of availability of water round the year and, Quality is measured based on the perceptions of the people about water quality. Urban Water Supply and Sanitation Policy-2009 adopted three levels of services: Basic, medium, and high based on QARQ. Incorporating different levels of services in the rural context, two indicators below the basic level have been added to make altogether five levels (SNV, 2016).

Determination of service level through QAQR approach is helpful to analyse the difference in the service level in the various zones of the system even the similar service was intended to all populations. Differences in the service level can be caused by technical, managerial, and behaviour of the people. This is helpful to improve service level equitably in all parts of the system. It also needed to ensure the service level to the diverse group of people in the service area.

Distribution of WUSCs and households falling under different service levels in three of four QAQR components revealed that 78 percent of the schemes and scheme users' households are relying on sub-standard (40\%) or basic level (38\%) quality of water services. There exists no provision of highquality water services. Nearly 11 percent of the schemes and scheme users' households do not have any forms of quality water services and, some ten and a half percent are relying on the medium quality level of water services.

Table 4. Quality, Accessibility, Quantity and Reliability Criteria for Levelling Water Service

\begin{tabular}{|c|c|c|c|c|c|}
\hline Score & $\begin{array}{l}\text { Level of } \\
\text { service }\end{array}$ & Quality (test and Perception) & $\begin{array}{l}\text { Accessibility } \\
\text { Distance }\end{array}$ & $\begin{array}{c}\text { Quantity } \\
\text { (Litre/person/day) }\end{array}$ & $\begin{array}{c}\text { Reliability } \\
\text { (Month/year) }\end{array}$ \\
\hline 5 & High & $\begin{array}{l}\text { WHO guideline } \\
\text { (Very safe and clean) }\end{array}$ & Within house & $\geq 100$ & $\begin{array}{l}12 \text { months } \\
\text { (never fail) }\end{array}$ \\
\hline 4 & Medium & $\begin{array}{l}\text { National standard } \\
\text { (Safe and clean) }\end{array}$ & In compound & $45-100$ & $\begin{array}{l}12 \text { months } \\
\text { (Never fail) }\end{array}$ \\
\hline 3 & Basic & $\begin{array}{l}\text { National standard } \\
\text { (Safe all the time) }\end{array}$ & Within $100 \mathrm{~m}$ & $25-45$ & $>11$ months* \\
\hline 2 & $\begin{array}{l}\text { Substandard } \\
\text { (acceptable for } \\
\text { special case) }\end{array}$ & $\begin{array}{l}\text { Clean and Free from } \\
\text { bacteria(Unsafe some of the } \\
\text { time) }\end{array}$ & Within $200 \mathrm{~m}$ & $15-25$ & $\begin{array}{l}>11 \\
\text { months** }\end{array}$ \\
\hline 1 & No service & (Unsafe most of the time) & $\begin{array}{l}\text { Away from } \\
200 \mathrm{~m}\end{array}$ & $<15$ & $\begin{array}{l}<11 \\
\text { months*** }\end{array}$ \\
\hline & sunnly hreak & vs in a vear is more than 60 & $\begin{array}{l}\text { s however con } \\
\text { s however con } \\
\text { s or continuou. }\end{array}$ & breakdown is not $\mathrm{n}$ & $\begin{array}{l}\text { e than one day } \\
\text { e than two days }\end{array}$ \\
\hline
\end{tabular}

A review of the accessibility to water services indicated that 64 percent of user households are relying on basic (distance to tap is within 100 metre from home), 14 percent on medium (water tap Nepalese Journal of Development and Rural Studies, Volume 17 
in the household compound) service, nearly 12 percent in sub-standard service (between 100 and 200 metres from home), and mere less than two percent have access to high standard water services. The rest eight percent of the households totally abstained from any forms of water accessibility services. On the contrary, 60 percent of the scheme users' households were found getting 100 or more litres of water per person in a day - categorising as high-quality service and, 27 percent of the water user households getting less than 14 litres of water, meaning no service at all.

\section{The Priority Ranking Indicators}

Ten priority indicators used by the SNV report (2016) are also assessed to calculate procedural approaches and governance issues to lead the scheme towards sustainability. Those indicators are assigned score 1 in case of absence of priority activity and 5 in case actively or highly presence of the same. The score achieved by each priority component then is summed up to determine how effectively the schemes have given priority to accomplish the process or activity. A scheme that meets all priority criteria in total is likely to score 50 points and a scheme in the absence of all criteria scores 10 points. Hence, the minimum priority ranking score for a scheme will be 10 and a maximum of 50 . Schemes scoring 30 points, and above in total are considered sustainable, between 20 and 30 partially sustainable and less than 20 un-sustainable. The priority ranking indicators are:

- Existence of WUSC at present (time of the survey, no=1, yes=5)

- WUSC is active in operation, repairs, and providing water services to users $(\mathrm{no}=1$, yes $=5$ )

- WUSC membership complies with GoN requirement for female representation (none $=1,<10 \%=2$, $10-20 \%=3 ; 20-32 \%=4$ and $33 \%=>5$ )

- Caste/ethnic composition of WUSC membership i.e. distribution of Dalit and Janajati (none=1; up to $10 \%=2 ; 10-20 \%=3 ; 21-32 \%=4$ and $33 \%=>5$ )

- Water source conservation and protection of hazardous areas (None=1, Awareness building programme $=2$, and Conservation of catchment area $=5$ ).

- Existence of Bank Account of WUSC (none=1, yes =5)

- $\quad$ Registration of WUSC with DWRC (none=1, yes =5)

- Annual general meeting-AGM of WUSC (none=1, yes =5)

- $\quad$ Public Audit of WUSC (none=1, yes =5)

- $\quad$ Registration of WUSC with FEDWASUN (none=1, yes =5).

The total score achieved by a scheme out of 50 is classified into three groups as unsustainable achieving less than 20: partially sustainable scoring between 20 and 30 and sustainable achieving 30 and more score (Table 5). Percent of distribution of the schemes and users' households summarised in Table 4 has cleared that 55 percent are in the state of partial sustainability, which means simple efforts leads those towards full sustainability, a bit above one-third (34\%) are in the state of full sustainability and the rest 11 percent in an unsustainable state. This implied that the majority of the schemes (55\%) need priority support to upgrade their status into full-sustainable and 11 percent in the second priority after partially sustainable schemes exhibit a robust sign of full sustainability. 
Table 5. Percentage Distribution of Wuscs and Scheme User Households According to Priority Ranking Sustainability by Background Attributes

\begin{tabular}{|c|c|c|c|c|c|c|}
\hline \multirow{3}{*}{$\begin{array}{c}\text { Background } \\
\text { Attributes }\end{array}$} & \multicolumn{5}{|c|}{ Sustainability in Priority Ranking } & \multirow{3}{*}{$\begin{array}{c}\% \text { Toward } \\
\text { Sustainability }\end{array}$} \\
\hline & \multirow{2}{*}{$\begin{array}{c}\text { Un- } \\
\text { sustainable }\end{array}$} & \multirow{2}{*}{$\begin{array}{l}\text { Partially } \\
\text { Sustainable }\end{array}$} & \multirow[t]{2}{*}{ Sustainable } & \multicolumn{2}{|c|}{ Total } & \\
\hline & & & & $\%$ & $\mathbf{N}$ & \\
\hline \multicolumn{7}{|l|}{ Survey Districts } \\
\hline Palpa & 10.0 & 75.0 & 15.0 & 100.0 & 680 & 90.0 \\
\hline Nawalparasi & 12.5 & 35.0 & 52.5 & 100.0 & 680 & 87.5 \\
\hline \multicolumn{7}{|l|}{ Geographic Area } \\
\hline Tarai & 22.2 & 22.2 & 55.6 & 100.0 & 306 & 77.8 \\
\hline Hill & 8.1 & 64.5 & 27.4 & 100.0 & 1,054 & 91.9 \\
\hline \multicolumn{7}{|l|}{ Caste/Ethnicity } \\
\hline $\mathrm{BCT}$ & 8.6 & 52.6 & 38.8 & 100.0 & 430 & 91.4 \\
\hline Janajati & 12.7 & 59.7 & 27.6 & 100.0 & 722 & 87.3 \\
\hline Dalit & 11.5 & 43.8 & 44.7 & 100.0 & 208 & 88.5 \\
\hline \multicolumn{7}{|l|}{ Phase of Scheme } \\
\hline First & 10.5 & 50.0 & 39.5 & 100.0 & 646 & 89.5 \\
\hline Second & 7.1 & 67.9 & 25.0 & 100.0 & 476 & 92.9 \\
\hline Third & 21.4 & 42.9 & 35.7 & 100.0 & 238 & 78.6 \\
\hline \multicolumn{7}{|l|}{ Size of Scheme } \\
\hline Small & 11.9 & 59.3 & 28.8 & 100.0 & 1,003 & 88.1 \\
\hline Big & 9.5 & 42.9 & 47.6 & 100.0 & 357 & 90.5 \\
\hline \multicolumn{7}{|l|}{ Sources of Water } \\
\hline Spring=Only & 7.3 & 65.9 & 26.8 & 100.0 & 697 & 92.7 \\
\hline Stream/River & 23.5 & 35.3 & 41.2 & 100.0 & 289 & 76.5 \\
\hline Spring/stream & 9.1 & 50.0 & 40.9 & 100.0 & 374 & 90.9 \\
\hline Total & 11.3 & 55.0 & 33.8 & 100.0 & 1,360 & 88.8 \\
\hline
\end{tabular}

Over 50 percent schemes in Nawalparasi, that of the Tarai region; over 40 percent of the Dalit communities, big in size, and stream/river and spring/stream water sourced are in the state of full sustainability. Likewise, three-fourth (75\%) of the schemes in Palpa, 68 percent of the second phase and 65 percent in the hill regions are in the state of partial sustainability. The extent of the unsustainable scheme is found to be high in the Tarai region that of the third phase and stream/river water sourced (over $21 \%$ in each). 


\section{Aggregating the Institutional and Governance Level Sustainability}

A single composite indicator of the following 12 criterion of social/community participation and practices of good governance is constructed to see the level of social and governance aspect of sustainability of an RWSS. A 0, 1 dichotomous dummy of each 10 characteristics of a RWSS is created. If anRWSS satisfies a specific characteristic assign a score 1 otherwise 0 and weighted by 10 . Any scheme achieved less than 0.33 score categorised as totally unsustainable, in between 0.33 to 0.5 partially sustainable and above 0.5 scores as towards fully sustainable. The considered characteristics are:

1. Registration status at district water resource committee (DWRC), and affiliation with FEDWASUN

2. Scheme held six and more meetings of the working committee in the last 12 months

3. Scheme held two and more mass meetings of the users' community in the last year

4. Scheme called an annual general meeting (AGM) in the last 12 months, and made public its income-expenditure statement

5. The scheme has female members in key positions and Dalits and Janajati members in a working committee

6. Members of the working committee and key positions are selected/elected either by voting or by consensus from the mass or annual general meeting

7. Decisions in the meeting related to longer-term functionality of the scheme are made through extensive discussions in the meeting

8. The scheme has developed a users' feedback collection system

9. Scheme has developed a public audit system in place

10. WUSCs participation in the design of the scheme was 'good' or 'very good'.

The achieved sustainability score indicated that 76 percent of the schemes and user households are in a sustainable position and less than one-fifth i.e. 24 percent are unsustainable (Figure 3). Sustainability varies by district and other attributes of observation. Since nearly 83 percent of the schemes in Nawalparasi against 70 percent in Palpa are sustainable. Likewise, 79 percent of user households of the Brahman/Chhetri and Thakuri communities are in a sustainable state, and 86 percent of the big schemes. Institutional and governance sustainability is found to be the lowest in the case of stream/river water sources (59\%) followed by Palpa (70\%). 


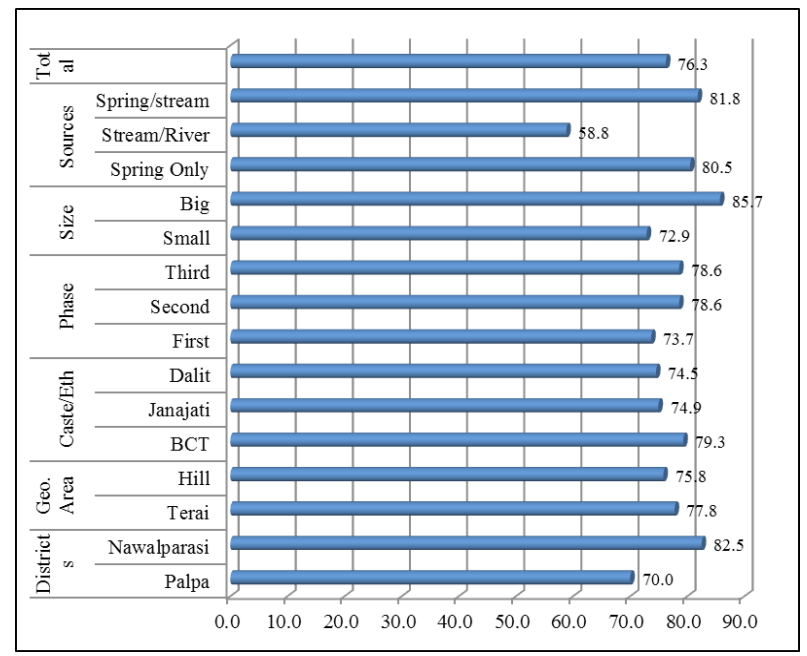

\section{Figure 3. Percent of Schemes Sustainable in Institutional and Governance Issues}

The schemes that achieved a sustainability score of zero or less than ten percentage points account for nearly one percent each $(1.3 \%)$, and that are sustainable in two characteristics account for five percent and some 16 percent scored 25 percentage points (i.e. meet at least three attributes of sustainability). The schemes that meet only the threshold score of sustainability (i.e. one-third) account for 22.5 percent and nearly nine schemes were found to achieve 67 percent i.e. maximum in the range. Higher proportions of the schemes in Nawalparasi, the Tarai region, resided by the Dalit community were found to have achieved the highest score of sustainability (i.e. above 67\%).

\section{Discussion and Conclusion}

It is obvious to conclude that scheme's functionality status in terms of the proportion of the working taps to the total taps constructed at the beginning of the scheme, the number of households sharing a functional tap, and months of water availability in the taps (on uninterrupted basis) is highly sustainable. However, the schemes are needed to put their best efforts into improving per-second water flow in the taps and improving the quality of water during the wet season. From the point of view of quantity, accessibility, reliability, and quality aspects of service level, the water service of RWSS are at an intermediate level in the case of quality and accessibility components; however, it is at a satisfactory level in the case of proportion to getting high standard quantity service and reliability services. On the whole, compositing score of the schemes with reference to institutional management and good governance revealed that a bit less than one-fourth (24\%) are unsustainable as they achieved less than 33 percent score; a majority (55\%) of are partially sustainable, and a bit more than one-fifth (21\%) achieved seven and more scores and they are categorised fully sustainable.

However, social or governance level sustainability of RWSS well exhibited that of the geographical variation, since, schemes of hill region are relatively in batter level than that of Tarai. Caste/ethnic variation persists in mitigating the functionality of WUSCs. WUSCs of majority resided by Brahman, Chhetry, and Thakuri seem to achieve a higher score of sustainability than that of 
Dalits. Overall, it could be concluded that schemes achieved sustainability in social and governance components of management, would be in a position to gain sustainability in technical, financial, and environmental components of functioning.

\section{References}

ICSU \& ISSC (2015). Review of the Sustainable Development Goals: The Science Perspective. Paris: International Council for Science (ICSU).

Lenton, K., L. \& Wright, A. M. (2008). Water, sanitation and the millennium development goals. Journal of International Affairs, 61(2), 247-258. Retrieved fromhttp://www.jstor.org/ stable/ Accessed on 06-04-2016.

MoUD (2014). National water supply and sanitation sector policy 2014. Kathmandu: Government of Nepal, Ministry of Urban Development (GoN/MoUD).

Pahl-Wostl, C., Mostert, E., \& Tabara, D. (2008). The Growing importance of social learning in water resources management and sustainability science. Ecology and Society, 13(1) 24. Retrieved from http://www. ecologyandsociety.org/vol13/iss1/art24/. Accessed on: 04/07/2016.

SNV (2016). Functionality of rural water supply system: Integrated training package for post construction support service team. Kathmandu: SNV Nepal, March 2016.

WFD- the EU Water Framework Directive (2000). WFD - introduction and overview, integrated river basin management for Europe. Retrieved from https://ec.europa.eu/environment/ water/ water-framework/index_en.html. Accessed on 6 February, 2021). 